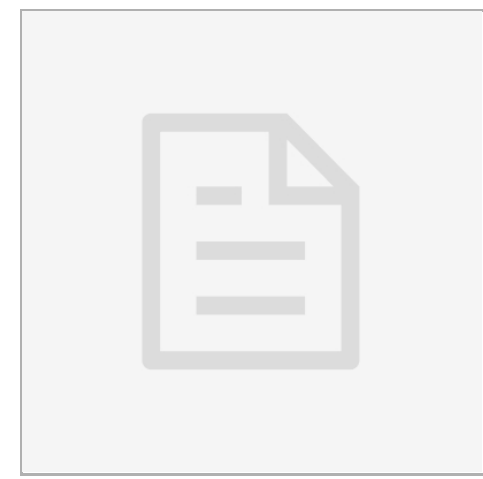

JUL 31, 2021

OPEN $\boldsymbol{\bigodot}$ ACCESS

DOI:

dx.doi.org/10.17504/protocol

s.io.bswanfae

Collection Citation: Odetta Antico, Miratul M. Muqit 2021. Cell-based analysis of PINK1Parkin pathway activation in primary mouse cortical neurons. protocols.io https://dx.doi.org/10.17504/p rotocols.io.bswanfae

License: This is an open access collection distributed under the terms of the Creative Commons Attribution License, which permits unrestricted use, distribution, and reproduction in any medium, provided the original author and source are credited

Protocol status: Working We use this protocol and it's working

Created: Mar 01, 2021

Last Modified: Dec 26, 2022

\section{(3) Cell-based analysis of PINK1-Parkin pathway activation in primary mouse cortical neurons} \author{
$5 \mathrm{EH}, \mathrm{UK}$

$$
\text { ASAP2020 alessi }
$$

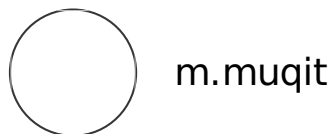

Odetta Antico ${ }^{1}$, Miratul M. Muqit ${ }^{1}$

1Medical Research Council Protein Phosphorylation and Ubiquitylation Unit, School of Life Science, University of Dundee, Dow Streets, Dundee, DD1

\section{ABSTRACT}

Mutations in PINK1 cause early-onset Parkinson's disease. PINK1 becomes stabilised and active upon mitochondrial depolarisation. This leads to phosphorylation of ubiquitin and Parkin via Serine 65 residues and a feed forward mechanism whereby PINK1 phosphorylates newly formed polyubiquitin chains, generating phosphoubiquitin, which further promotes Parkin recruitment and activation. Once activated, Parkin ubiquitylates proteins at the outer face of the outer mitochondrial membrane (OMM) and then initiates a downstream pathway that eventually leads to mitophagy, a mitochondria-specific type of autophagy. Notably, much of previous investigation into PINK1/Parkin activity has been performed in non-neuronal human cancer cells where Parkin and/or PINK1 is over-expressed. Here we report a protocol for generation of mouse embryonic cortical neuronal cultures that produce high cell yields and can be used for studying endogenous PINK1 and Parkin signalling by biochemical methods and proteomics.

\section{ATTACHMENTS}

Mouse PINK1 pathway protocol (166 - 337).pdf

\section{8}

Keywords: Neurons, PINK1, Parkin, Mitochondrial stress, ubiquitin, ASAPCRN 


$$
\begin{aligned}
& \text { Mouse PINK1 } \\
& \text { pathway } \\
& \text { protocol (166 } \\
& \text { - 337).pdf }
\end{aligned}
$$

\section{FILES}

\section{Protocol}

NAME

PROCEDURE TO INDUCE MITOCHONDRIAL DEPOLARISATION AND LYSING OF MOUSE CORTICAL NEURONS

\section{VERSION 1}

CREATED BY

m.muqit

OPEN $\rightarrow$

\section{Protocol}

NAME

PROCEDURE TO ISOLATE AND CULTURE NEURONS FROM EMBRYONIC MOUSE CORTEX

\section{VERSION 1}

CREATED BY

m.muqit 